\title{
Dialysis Care for U.S. Military Veterans in Puerto Rico during the 2017 Atlantic Hurricane Season, a Retrospective Cohort Study
}

Lilia Lukowsky ( $\sim$ Lilia.Lukowsky@va.gov)

US Department of Veterans Affairs https://orcid.org/0000-0003-2508-6173

Aram Dobalian

US Department of Veterans Affairs

Kamyar Kalantar-Zadeh

University of California Irvine

Claudia Der-Martirosian

US Department of Veterans Affairs

Research article

Keywords: ESRD, hemodialysis, Veterans Affairs

Posted Date: August 25th, 2020

DOI: https://doi.org/10.21203/rs.3.rs-54797/v1

License: (c) (i) This work is licensed under a Creative Commons Attribution 4.0 International License.

Read Full License 


\section{Abstract}

Continuity of care for End Stage Renal Disease (ESRD) patients is critical as they are at heightened risk for increased morbidity and mortality if their typically 3-times a week hemodialysis treatment is interrupted because of disaster-related disruptions in equipment, electricity, water, communication, or transportation.(1-4) For example, a month after Hurricane Katrina (2005), more than $50 \%$ of the dialysis facilities in Louisiana were still closed due to major damage caused by the hurricane.(5) These closures contributed to an increase in renal-related hospitalizations in the hurricane-affected areas.(6),(7) Similarly, during Hurricane Sandy (October 29, 2012), 306 dialysis facilities in New York and New Jersey were closed right after the hurricane struck.(2) Major disruptions in dialysis services caused by Sandy led to missed dialysis care during the first week post-Sandy for both U.S. Department of Veterans Affairs (VA) and non-VA patients. Major disruptions in dialysis services might have contributed to an increase in the 30-day mortality rate of $1.83 \%$ in Sandy-affected areas compared to $1.6 \%$ for the same month in the preceding year. $(5,8)$

\section{Introduction}

Continuity of care for End Stage Renal Disease (ESRD) patients is critical as they are at heightened risk for increased morbidity and mortality if their typically 3-times a week hemodialysis treatment is interrupted because of disaster-related disruptions in equipment, electricity, water, communication, or transportation.(1-4) For example, a month after Hurricane Katrina (2005), more than $50 \%$ of the dialysis facilities in Louisiana were still closed due to major damage caused by the hurricane.(5) These closures contributed to an increase in renal-related hospitalizations in the hurricane-affected areas.(6),(7) Similarly, during Hurricane Sandy (October 29, 2012), 306 dialysis facilities in New York and New Jersey were closed right after the hurricane struck.(2) Major disruptions in dialysis services caused by Sandy led to missed dialysis care during the first week post-Sandy for both U.S. Department of Veterans Affairs (VA) and non-VA patients. Major disruptions in dialysis services might have contributed to an increase in the 30-day mortality rate of $1.83 \%$ in Sandy-affected areas compared to $1.6 \%$ for the same month in the preceding year. $(5,8)$

Dialysis dependent patients due to ESRD require established vascular access so they can receive dialysis treatments.(9) There are three types of vascular access: arteriovenous fistula (AVF), arteriovenous graft (AVG), and central venous catheter (CVC). AVF is considered the safest and currently the most commonly used method. However, a placement of AVF requires surgery and requires usually two or more before it can be used for treatment. Therefore, during emergency dialysis initiation another vascular access method, most likely a CVC, needs to be used before switching to AVF in subsequent months. The vascular access site has to be monitored on a daily basis by the patient and medical personnel to prevent complications such as infections, stenosis, or thrombosis. $(9,10)$ Complications associated with all types of vascular access have been widely reported in the literature, and can arise at the time of access placement as well as during the maintenance period.(11-14) While complications associated with vascular access are common among ESRD patients, during and immediately after a disaster they can 
become exacerbated due to shortages of clean water, electricity, and transportation, as well as limited access to dialysis facilities.

In Puerto Rico after Hurricanes Irma and Maria (September 2017), damage to major infrastructure caused delays in medical care throughout most of the island, and resulted in more $\$ 50$ billion dollars in damages.(15-18) The electrical grid suffered significant damage, leaving the majority of the island's population without power until November 2017 although outages continued through May 2018.(16) Even though 48 out of 58 hemodialysis (HD) units opened almost immediately using generators and water tanks following hurricane Maria, Bonilla-Felix et al. (2019)(3) reported that road damage, fallen power lines, and a shortage of fuel were major barriers accessing dialysis facilities. By October 2017, about one month after the hurricanes, all but 33 out of the 6,000 ESRD patients on the island had at least one contact with their dialysis provider.(18) It was also reported that 600 dialysis patients left the island within a year after Maria.(3)

Prior to the hurricanes, the dialysis unit at the San Juan VA Medical Center (SJVAMC) provided regular outpatient dialysis care to Veterans with ESRD. Additionally, the SJVAMC dialysis unit provided inpatient dialysis to Veterans with ESRD during their hospitalizations, as well as inpatient dialysis to patients with

acute kidney failure (AKF). During and after the two hurricanes, the dialysis unit at the SJVAMC remained open and continued serving its Veteran patient population. Some VA patients with ESRD who were not receiving maintenance hemodialysis at the SJVAMC prior the hurricanes, were treated at the SJVAMC dialysis unit after the two hurricanes, most likely because they were unable to access their regular non-VA treatment sites.

In this study, we examine how Irma and Maria affected access to dialysis care for VA ESRD patients at both the SJVAMC and non-VA community clinics. We hypothesize that SJVAMC experienced an increase in its volume of dialysis care after the hurricanes because of the aforementioned challenges to delivering care at non-VA dialysis clinics in Puerto Rico.

\section{Methods}

\section{Cohort Description}

We conducted a retrospective, longitudinal cohort study using VA administrative and clinical data from the VA Corporate Data Warehouse. The Puerto Rico ESRD cohort of VA users was defined as VA patients who had at least one dialysis-related encounter on Puerto Rico or the U.S. Virgin Islands one year before and one year after the 2017 hurricane season between 9/06/2016 and 9/5/2018. We used Current Procedural Terminology (CPT) codes 90935-90937, 90945-90947, 90960-90962, 90999 and G0257 to identify procedures related to dialysis treatments at the SJVAMC dialysis unit and non-VA dialysis centers. We also examined visits related to vascular access for dialysis using 101 CPT codes associated with the placement of CVC, AVF or AVG as well as with complications for vascular access.

\section{Analysis}


We compared the annual number of dialysis encounters a year before to a year after the hurricanes at the SJVAMC and non-VA facilities. The number of visits to an emergency department (ED) was also examined one year before and one year after. Chi-square tests were used to analyze the differences between pre- and post- hurricanes visits to the VA facilities. Additionally, we assessed the number of visits related to dialysis vascular access (either due to a placement, a change, or for complications associated with it).

We fitted a random effect logistic regression model(19) for correlated binary outcomes comparing mortality between pre- and post-hurricane periods while accounting for the fact that some patients used SJVAMC during both periods and therefore observations for those patients were not independent as they were included in both the before and after groups. The model adjusted for time-dependent covariates, including age as well as co-morbidities (hypertension, diabetes, heart failure (HF), pulmonary vascular disease (PVD), and sepsis). Models of this type are commonly used for outcomes that change over time to accurately estimate both subject-specific effect, accounting for multiple data points for the same subject, as well as between subject effects.(20)

All analyses were performed using the SAS 9.4 and SAS Enterprise Guide 7.1 software packages (SAS Institute, Cary NC). Proc GLIMMIX was used to fit a random effect model. This study was approved by the [author institution] Institutional Review Board.

\section{Results}

\section{Patient characteristics}

The study cohort included 330 ESRD patients who received at least one hemodialysis treatment in Puerto Rico: 195 who received all dialysis services at the SJVAMC, 20 who used only non-VA dialysis clinics, and 115 who received dialysis care at both VA and non-VA clinics. We identified 58 ESRD patients that received maintenance hemodialysis exclusively at SJVAMC during the study period (38 received hemodialysis a month before the hurricanes). Table 1 illustrates the demographic characteristics and comorbid diagnoses before and after the hurricanes. With regard to demographic characteristics, $98 \%$ were men, $59 \%$ were married, $22 \%$ were divorced or separated, $10 \%$ were never married, and $9 \%$ were widowed, $81 \%$ were age 65 or older (mean age 73; range 38-98), and the average distance from patients' home to SJVAMC was 19 km (12 miles) (see Table 1, column 3). With regard to comorbid diagnoses, 70\% had diabetes, 79\% had hypertension, $51 \%$ had heart failure, 39\% had ischemic heart disease, 36\% had sepsis, and $37 \%$ had at least one diagnosis of infection other than sepsis during the study period (see Table 1, Total Column). Between September 2017 and January 2018, three ESRD non-VA patients who had evacuated from the Virgin Islands after Hurricane Irma were treated at the SJVAMC. All three received inpatient dialysis in Puerto Rico and were included in this study. During the two-year study period, there were 115 (35\%) deaths and 8 (2\%) patients received kidney transplant. Additionally, 224 (68\%) ESRD patients had at least one outpatient encounter related to a vascular access (see Table 1, Total Column). 
Table 1

VA ESRD patient characteristics in Puerto Rico, pre/post Hurricanes Irma and Maria ( $\mathrm{N}=330)$

\begin{tabular}{|c|c|c|c|}
\hline Patient Demographics & $\begin{array}{l}\text { Pre-Hurricanes Irma \& } \\
\text { Maria }(\mathrm{N}=239)\end{array}$ & $\begin{array}{l}\text { Post- } \\
\text { Hurricanes } \\
\text { Irma \& Maria } \\
(\mathrm{N}=251)\end{array}$ & $\begin{array}{l}\text { Total } \\
(\mathrm{N}= \\
330)\end{array}$ \\
\hline Male & $237(99 \%)$ & $247(98 \%)$ & $\begin{array}{l}326 \\
(98 \%)\end{array}$ \\
\hline Married & $150(63 \%)$ & $145(58 \%)$ & $\begin{array}{l}194 \\
(59 \%)\end{array}$ \\
\hline Never Married & $22(9 \%)$ & $26(10 \%)$ & $\begin{array}{l}31 \\
(10 \%)\end{array}$ \\
\hline Divorced/Separated & $45(18 \%)$ & $56(22 \%)$ & $\begin{array}{l}74 \\
(22 \%)\end{array}$ \\
\hline Widowed & $21(9 \%)$ & $23(9 \%)$ & $\begin{array}{l}30 \\
(9 \%)\end{array}$ \\
\hline Mean Age (range) & $72(38-98)$ & $72(38-97)$ & $\begin{array}{l}72 \\
(37- \\
98)\end{array}$ \\
\hline \multicolumn{4}{|l|}{ Age Categories } \\
\hline $18-44$ & $1(0 \%)$ & $1(0 \%)$ & $1(0 \%)$ \\
\hline $45-64$ & $48(20 \%)$ & $50(20 \%)$ & $\begin{array}{l}63 \\
(19 \%)\end{array}$ \\
\hline $65+$ & $190(79 \%)$ & $200(80 \%)$ & $\begin{array}{l}266 \\
(81 \%)\end{array}$ \\
\hline \multicolumn{4}{|l|}{ Comorbidities } \\
\hline Heart Failure ** & $84(35 \%)$ & $120(47 \%)$ & $\begin{array}{l}171 \\
(51 \%)\end{array}$ \\
\hline Ischemic heart disease & $73(31 \%)$ & $81(32 \%)$ & $\begin{array}{l}128 \\
(39 \%)\end{array}$ \\
\hline Hypertension & $170(71 \%)$ & $174(69 \%)$ & $\begin{array}{l}261 \\
(79 \%)\end{array}$ \\
\hline Pulmonary Vascular Disease (PVD)* & $7(3 \%)$ & $19(8 \%)$ & $\begin{array}{l}24 \\
(7 \%)\end{array}$ \\
\hline
\end{tabular}

Chi-square tests: ${ }^{\star} p<0.05 ;{ }^{\star \star} p<0.001 ;{ }^{* \star \star} p<0.0001$

${ }^{\wedge}$ Encounters include establishing vascular access at time of dialysis initiation, changing the access, and visits for complications associated with vascular access 


\begin{tabular}{|c|c|c|c|}
\hline Patient Demographics & $\begin{array}{l}\text { Pre-Hurricanes Irma \& } \\
\text { Maria }(\mathrm{N}=239)\end{array}$ & $\begin{array}{l}\text { Post- } \\
\text { Hurricanes } \\
\text { Irma \& Maria } \\
(\mathrm{N}=251)\end{array}$ & $\begin{array}{l}\text { Total } \\
(\mathrm{N}= \\
330)\end{array}$ \\
\hline Anemia & $119(50 \%)$ & $111(44 \%)$ & $\begin{array}{l}195 \\
(59 \%)\end{array}$ \\
\hline Parathyroid conditions & $14(6 \%)$ & $6(2 \%)$ & $\begin{array}{l}16 \\
(5 \%)\end{array}$ \\
\hline Diabetes & $161(67 \%)$ & $161(64 \%)$ & $\begin{array}{l}232 \\
(70 \%)\end{array}$ \\
\hline Cancer & $49(21 \%)$ & $48(19 \%)$ & $\begin{array}{l}92 \\
(28 \%)\end{array}$ \\
\hline Hepatitis (any type) * & $24(10 \%)$ & $11(4 \%)$ & $\begin{array}{l}33 \\
(10 \%)\end{array}$ \\
\hline HIV & $3(1 \%)$ & $4(1 \%)$ & $7(2 \%)$ \\
\hline Sepsis & $64(27 \%)$ & $63(25 \%)$ & $\begin{array}{l}118 \\
(36 \%)\end{array}$ \\
\hline Other infections & $63(26 \%)$ & $66(26 \%)$ & $\begin{array}{l}122 \\
(37 \%)\end{array}$ \\
\hline Mental health diagnoses & $111(46 \%)$ & $117(47 \%)$ & $\begin{array}{l}188 \\
(57 \%)\end{array}$ \\
\hline Opioid addiction & $2(1 \%)$ & $3(1 \%)$ & $4(1 \%)$ \\
\hline \multicolumn{4}{|l|}{ Other Characteristics } \\
\hline $\begin{array}{l}\text { Median distance to SJVAMC from home } \\
\text { address, in km (range) }\end{array}$ & $20(0-141)$ & $18(0-170)$ & $\begin{array}{l}19(0- \\
170)\end{array}$ \\
\hline $\begin{array}{l}\text { Median driving time to SJVAMC from home } \\
\text { address, in min (range) }\end{array}$ & $29(2-178)$ & $25(2-167)$ & $\begin{array}{l}20(2- \\
178)\end{array}$ \\
\hline Deaths & $50(21 \%)$ & $65(26 \%)$ & $\begin{array}{l}115 \\
(35 \%)\end{array}$ \\
\hline Any vascular access encounters ${ }^{\wedge}$ & $130(54 \%)$ & 139 (55\%) & $\begin{array}{l}224 \\
(68 \%)\end{array}$ \\
\hline Kidney transplant & $3(1 \%)$ & $5(2 \%)$ & $8(2 \%)$ \\
\hline \multicolumn{4}{|c|}{ Chi-square tests: ${ }^{*} p<0.05 ;{ }^{* \star} p<0.001 ; * \star \star p p<0.0001$} \\
\hline
\end{tabular}

During the year prior to the two hurricanes, 239 ESRD patients received dialysis care either at SJVAMC or at community clinics for which their case was paid by VA, compared to 251 patients in the year following 
the hurricanes (see Table 1, Pre and Post Columns). There were $50(21 \%)$ deaths during the pre-hurricane period $(9 / 6 / 16-9 / 5 / 17)$, and $65(26 \%)$ during the post-hurricane period $(9 / 6 / 17-9 / 6 / 18)$. There were no significant differences between patient characteristics during pre- and post- periods except for the number of patients with heart failure diagnosis at $84(33 \%)$ vs. $120(47 \%)(p<0.001)$, PVD at $7(3 \%)$ vs. 19 $(8 \%)(p<0.05)$, and hepatitis at $24(10 \%)$ vs. $11(4 \%)(p<0.05)$.

Table 2 provides information regarding patient characteristics based on mortality status during both preand post-hurricane periods. Diagnoses for ischemic heart disease (IHD) $(14(28 \%)$ vs. $29(45 \%), p<0.05)$ and PVD $(3(6 \%)$ vs. $8(12 \%), p<0.05)$ increased significantly for patients who died after the hurricane compared to patients who died before the hurricanes. 
Table 2

VA ESRD patient characteristics in Puerto Rico, pre/post Hurricanes Irma and Maria by mortality status $(\mathrm{N}=330)$

\begin{tabular}{|c|c|c|c|c|}
\hline \multirow[b]{2}{*}{ Patient Demographics (\%) } & \multicolumn{2}{|c|}{ Pre-Hurricanes $(\mathrm{N}=233$ ) } & \multicolumn{2}{|c|}{ Post-Hurricanes $(\mathrm{N}=251)$} \\
\hline & $\begin{array}{l}\text { Died pre- } \\
\text { hurricanes N } \\
=50(100 \%)\end{array}$ & $\begin{array}{l}\text { Did not die pre- } \\
\text { hurricanes } \mathrm{N}= \\
189(100 \%)\end{array}$ & $\begin{array}{l}\text { Died pos- } \\
\text { hurricanes N } \\
=65(100 \%)\end{array}$ & $\begin{array}{l}\text { Did not die post- } \\
\text { hurricanes } \mathrm{N}= \\
186(100 \%)\end{array}$ \\
\hline Male & $50(100 \%)$ & $186(98 \%)$ & $65(100 \%)$ & $182(98 \%)$ \\
\hline Married & $30(60 \%)$ & $120(63 \%)$ & $36(55 \%)$ & $109(59 \%)$ \\
\hline Never Married & $4(8 \%)$ & $18(10 \%)$ & $8(12 \%)$ & $18(10 \%)$ \\
\hline Divorced/Separated & $10(18 \%)$ & $35(19 \%)$ & $14(21 \%)$ & $42(23 \%)$ \\
\hline Widowed & $6(12 \%)$ & $15(8 \%)$ & $7(11 \%)$ & $16(9 \%)$ \\
\hline Mean Age (range) & $76(56-98)$ & $71(37-90)$ & $76(58-97)$ & $71(38-91)$ \\
\hline \multicolumn{5}{|l|}{ Age Categories } \\
\hline $18-44$ & 0 & $1(0 \%)$ & 0 & $1(0 \%)$ \\
\hline $45-64$ & $6(12 \%)$ & $42(22 \%)$ & $6(9 \%)$ & $44(24 \%)$ \\
\hline $65+$ & $44(89 \%)$ & $146(78 \%)$ & $59(91 \%)$ & $141(76 \%)$ \\
\hline \multicolumn{5}{|l|}{ Comorbidities } \\
\hline Heart Failure & $23(46 \%)$ & $67(35 \%)$ & $40(62 \%)$ & $80(43 \%)$ \\
\hline Ischemic heart disease * & $14(28 \%)$ & $59(31 \%)$ & $29(45 \%)$ & $52(28 \%)$ \\
\hline Hypertension & $27(54 \%)$ & $143(75 \%)$ & $35(53 \%)$ & 139 (75\%) \\
\hline $\begin{array}{l}\text { Pulmonary Vascular } \\
\text { Disease (PVD)* }\end{array}$ & $3(6 \%)$ & $4(2 \%)$ & $8(12 \%)$ & $11(6 \%)$ \\
\hline Anemia & $34(68 \%)$ & $85(45 \%)$ & $23(35 \%)$ & $88(47 \%)$ \\
\hline Parathyroid conditions & $3(6 \%)$ & $11(6 \%)$ & $2(3 \%)$ & $4(2 \%)$ \\
\hline Diabetes & $27(54 \%)$ & $134(71 \%)$ & $29(44 \%)$ & $132(71 \%)$ \\
\hline Cancer & $16(32 \%)$ & $33(17 \%)$ & $12(18 \%)$ & $36(19 \%)$ \\
\hline Hepatitis (any type) & $2(4 \%)$ & $22(12 \%)$ & $1(1 \%)$ & $10(5 \%)$ \\
\hline HIV & $2(4 \%)$ & $2(1 \%)$ & $2(1 \%)$ & $1(0 \%)$ \\
\hline Sepsis & 22 (44\%) & $42(21 \%)$ & $28(43 \%)$ & 35 (19\%) \\
\hline
\end{tabular}

Chi-square tests: ${ }^{*} p<0.05 ;{ }^{* \star} p<0.001 ;{ }^{* \star *} p<0.0001$ 


\begin{tabular}{|c|c|c|c|c|}
\hline \multirow[b]{2}{*}{ Other infections } & \multicolumn{2}{|c|}{ Pre-Hurricanes $(\mathrm{N}=233)$} & \multicolumn{2}{|c|}{ Post-Hurricanes ( $\mathrm{N}=\mathbf{2 5 1})$} \\
\hline & $19(38 \%)$ & $44(23 \%)$ & $19(29 \%)$ & $47(18 \%)$ \\
\hline Mental health diagnoses & $26(52 \%)$ & $85(45 \%)$ & 35 (54\%) & $82(4 \%)$ \\
\hline Opioid addiction & $1(0 \%)$ & $1(0 \%)$ & $1(0 \%)$ & $2(1 \%)$ \\
\hline \multicolumn{5}{|l|}{ Other Characteristics } \\
\hline $\begin{array}{l}\text { Median distance to } \\
\text { SJVAVA from home } \\
\text { address, in km (range) }\end{array}$ & $24(2-113)$ & $19(0-141)$ & $15(1-113)$ & $20(0-170)$ \\
\hline $\begin{array}{l}\text { Median driving time to } \\
\text { SJVAVA from home } \\
\text { address, in min (range) }\end{array}$ & $31(4-122)$ & $29(2-178)$ & $22(5-130)$ & $29(2-167)$ \\
\hline $\begin{array}{l}\text { Any vascular access } \\
\text { encounters }^{\wedge}\end{array}$ & $27(54 \%)$ & $103(55 \%)$ & $39(60 \%)$ & 100 (54\%) \\
\hline Chi-square tests: ${ }^{*} \mathrm{p}<0.0$ & $0.001 ; *$ & 001 & & \\
\hline
\end{tabular}

Figure 1 examines changes between pre- and post-hurricane season indicating a decrease in the total number of VA outpatient visits from 20,685 during the pre-hurricanes period to 18,092 after the hurricanes ( $14 \%$ decrease). While the number of dialysis visits decreased from 7,263 to 6,948 , the percent of dialysis visits out of the total number of visits increased from $35-38 \%(<0.001)$. There was an increase in both the number of ED visits during the post-hurricane period from 1,172 (5.7\%) to 1,195 (6.6\%) $(p<0.001)$, and in ESRD-related ED visits from $200(0.9 \%)$ to $227(1.3 \%)(p<0.05)$.

Table 3 shows age, period (pre-vs. post-hurricanes), and co-morbidity adjusted mortality odds ratios (ORs). Age (OR = 1.66; 1.23-2.17), co-morbid diagnoses such as heart failure $(\mathrm{OR}=2.07 ; 1.26-3.40)$, $P V D$ $(\mathrm{OR}=3.26 ; 1.28-8.28)$, and sepsis $(\mathrm{OR}=3.16 ; 1.89-5.29)$ were associated with higher mortality. Diabetes and hypertension were associated with lower mortality, with ORs $0.41(0.25-0.66)$ and $0.28(0.17-0.48)$, respectively. Even though there was $18 \%$ increase in mortality during the post-hurricane period $O R=1.18$ $(0.72-1.92)$, it was not statistically significant $(p=0.48)$. 
Table 3

Adjusted mortality Odds Ratios* for VA ESRD patients during pre- and posthurricanes Irma and Maria; $\mathrm{N}=330$.

\begin{tabular}{|llll|}
\hline Co-morbidity adjusted mortality odds ratios & OR & Cl & P \\
\hline Age (decades) & 1.66 & $1.23-2.17$ & 0.0002 \\
\hline Diabetes (ref = No) & 0.41 & $0.25-0.66$ & 0.0004 \\
\hline Hypertension (ref = No) & 0.28 & $0.17-0.48$ & $<0.0001$ \\
\hline PVD (ref = No) & 3.26 & $1.28-8.28$ & 0.01 \\
\hline HF (ref = No) & 2.07 & $1.26-3.40$ & 0.004 \\
\hline Sepsis (ref = No) & 3.16 & $1.89-5.29$ & $<0.0001$ \\
\hline Year of death (ref = pre-hurricanes) & 1.18 & $0.72-1.92$ & 0.48 \\
\hline
\end{tabular}

\section{Discussion}

On September 6, 2017, Hurricane Irma made landfall on Puerto Rico and caused significant damage to some parts of the island. Two weeks later on September 20,2017, Hurricane Maria, a major category 4 hurricane, caused major destruction and devastation to the entire island.(16) Even though most dialysis facilities on the island were able to reopen within a few days using generators and by making their own clean water, $(3,21)$ many ESRD patients encountered difficulties reaching their regular dialysis care sites because of road damage and transportation issues. Additionally, disruptions to power and telecommunications services made it impossible for many patients to communicate with their dialysis facilities. As in New York after Superstorm Sandy (2012),(22) the absence of medical records and dialysis documentation made the use of alternative dialysis facilities challenging and inefficient, which in turn resulted in delayed or even missed treatments in the first few weeks and even months after Irma and Maria.(21)

The dialysis unit at the San Juan VA Medical Center remained open during and after the hurricanes and continued providing services after the hurricanes. While other dialysis facilities reported about a $15 \%$ drop in their patient census through the month of December,(21) the SJVAMC dialysis unit saw an increase in the number of patients during the first month after the hurricanes (September-October of 2017), indicating minimal or no interruption of dialysis services.

In total, we observed an increase from 233 to 251 in the number of ESRD patients who used the SJVAMC dialysis clinic in the year following Irma and Maria although there was a substantial decrease in the general population on the island during that period. An analysis of geocoded tweets by Puerto Rico residents revealed that about $8.3 \%$ of the island residents relocated in the months following the hurricanes, and 4\% were still displaced by May 2018.(23) These numbers were somewhat higher for ESRD patients as it was reported that about $10 \%$ (600 out of 6,000$)$ of ESRD patients left Puerto Rico 
shortly before or after the hurricanes, and a small number of ESRD patients were medically evacuated to the mainland after Maria. $(23,24)$ While we do not have information about how many ESRD VA patients relocated from the island post-hurricanes, we do not expect this number to differ from non-VA dialysis patients. Therefore, the fact that more ESRD VA users sought care at the SJVAMC dialysis unit suggests that VA patients encountered difficulties accessing dialysis care at non-VA, community dialysis clinics after the hurricanes. Additionally, the fact that we saw very little difference in pre- and post-hurricane attendance among regular VA ESRD patients suggests that the excess number of dialysis patients at the SJVAMC after the hurricanes was mostly due to VA ESRD patients who previously received care in community settings before the hurricanes, but instead received at least some of their dialysis care at the SJVAMC after the hurricanes.

We observed an increase in the number of ESRD VA patients that either permanently or temporarily switched to receiving care from the VA dialysis unit rather than their regular community clinics, especially during September-October 2017. These observations might indicate that many ESRD patients used SJVAMC on an emergency rather than regular basis, most likely due to limited access to care in community settings. Large integrated healthcare delivery systems may be better able to handle postdisaster increased demands, i.e. surges, for care, even for extended periods lasting a few months, than smaller, standalone facilities. Even though there was an increase in the number of ESRD patients after the hurricanes, the total number of outpatient encounters and the number of dialysis visits decreased in the year following the hurricanes, perhaps because of departures from the island. Nonetheless, the percentage of dialysis visits and ED visits increased significantly following the hurricanes, indicating an overall increase in the acuity level for care. Additionally, we observed an increase in deaths among ESRD patients from $50(21 \%)$ during the pre-hurricane period compared to $65(26 \%)$ post-hurricanes, although this change was not statistically significant.

We found that age and various comorbid conditions such as PVD and IHD were significantly associated with mortality. In fact, we observed an increase from $6-12 \%$ for PVD and $28-45 \%$ for IHD. We also observed an increase in HF diagnoses in patients who died during the post-hurricanes period from 46$62 \%$, and an increase from $35-47 \%$ in all patients. Missed or delayed dialysis can lead to volume overload and heart failure. Indeed, we observed a significant increase in HF diagnoses in the posthurricane period, which could be related to limited access to dialysis services for the ESRD patients receiving dialysis at non-VA facilities right after the hurricanes. We did not observe any changes in dialysis schedules for the VA dialysis patients. That might be because SJVAMC remained open during the hurricanes. Most likely ESRD patients receiving dialysis at the VA lived in relatively close proximity to SJVAMC, and therefore were less affected by road closures and transportation issues.

We also observed a significant association between sepsis diagnosis and mortality, which may be related to the problems associated with vascular access as it often leads to infection. More than $50 \%$ of our study participants had procedures associated with vascular access. Also, $60 \%$ of patients who died after the hurricanes had vascular access-related visits, compared to $54 \%$ of those who died before the hurricanes. This might at least partially explain an association between mortality and sepsis diagnosis. 
While there was no difference in sepsis diagnoses between the pre- and post-hurricanes period, more than $40 \%$ of patients who died had a sepsis diagnosis compared to about $20 \%$ of those who did not.

\section{Strengths And Limitations}

Our study examined access to dialysis care by ESRD veteran patients after a major natural disaster. As the largest integrated healthcare system in the country, VA can provide resources to assist patients at a time when the local systems get overwhelmed after disasters.

For this study, we used VA administrative and clinical data that contain comprehensive information about all services VA users received at the VA healthcare system, as well as, services received outside of the VA, but paid by the VA. Additionally, we used data on patient demographic characteristics and diagnoses from hospitalizations and outpatient visits at the VA.

Our study has a few limitations. We had access to data from the United States Renal Data System (USRDS)(25) for calendar year 2016 through June 2017 because the availability of Medicare data usually lags about two years. Accordingly, we were unable to use Medicare information in our analysis. Therefore, we were unable to identify Puerto Rico ESRD cohort patients who were enrolled in Medicare after June 2017. Furthermore, we were unable to use the USRDS to determine the dates of dialysis initiation and the dialysis modalities at both the time of dialysis initiation and during the post-hurricane period. Additionally, we were unable to verify medical care for patients from our cohort if they left the island or received care that was not paid by the VA.

\section{Conclusion}

We examined the differences in outpatient encounters, dialysis care, and ED visits among ESRD patients who used VA or non-VA dialysis facilities during the year before and after Hurricanes Irma and Maria in Puerto Ricco. There were minimal or no interruptions of services for ESRD patients who were receiving dialysis on a regular basis at the SJVAMC during the year following the hurricanes. However, we observed an increase in the number of patients who received dialysis services at the SJVAMC during the immediate post-hurricane period, most likely due to limited access to dialysis care at the non-VA clinics. Our study shows that SJVAMC served as a safety net for VA ESRD patients after the hurricanes, regardless whether they were receiving dialysis care at VA or non-VA facilities prior to the hurricanes. These findings have important implications for dialysis services and dialysis resources at the VA, since they can assist nonveteran ESRD patients during disasters and pandemics.

\section{Abbreviations}

AKF Acute Kidney Failure

AVF arteriovenous fistula 
AVG arteriovenous graft

CPT Current Procedural Terminology

CVC central venous catheter

ED Emergency Department

ESRD End Stage Renal Disease

HD hemodialysis

HF Heart Failure

IHD Ischemic Heart Disease

OR odds ratio

PVD Pulmonary Vascular Disease

SJVAMC San Juan VA Medical Center

VA U.S. Department of Veterans Affairs

\section{Declarations}

\section{Ethics approval and consent to participate:}

This study was approved by the U.S. Department of Veterans Affairs (VA) Greater Los Angeles Healthcare System Institutional Review Board.

\section{Consent for publication:}

Not applicable since the study conducted secondary data analysis.

\section{Availability of data and materials:}

The datasets generated and/or analyzed during the current study are not publicly available since the data could potentially identify some of the respondents when linked to other data, but are available from the corresponding author on reasonable request.

\section{Competing interests:}

The authors declare that they have no competing interests. 


\section{Funding:}

This study was funded by the U.S. Department of Veterans Affairs. The funder did not participate in the design of the study, collection, analysis, and interpretation of data or writing this manuscript.

\section{Authors' contributions:}

$\mathrm{LL}$ and CDM participated in the design and analysis of the study data. All authors participated in interpretation of data and in the writing of the manuscript. All authors read and approved the final manuscript.

\section{Acknowledgements:}

This material is based upon work supported by the U.S. Department of Veterans Affairs, Veterans Health Administration, Office of Patient Care Services. The views expressed in this article are those of the authors and do not necessarily represent the position or policy of the U.S. Department of Veterans Affairs or the United States government.

\section{References}

1. Murakami N, Siktel HB, Lucido D, Winchester JF, Harbord NB. Disaster preparedness and awareness of patients on hemodialysis after Hurricane Sandy. Clin J Am Soc Nephrol. 2015;10(8):1389-96.

2. Lempert KD, Kopp JB. Hurricane Sandy as a kidney failure disaster. American journal of kidney diseases: the official journal of the National Kidney Foundation. 2013;61(6):865.

3. Bonilla-Felix M, Suarez-Rivera M. Disaster Management in a Nephrology Service: Lessons Learned from Hurricane Maria. Blood Purif. 2019;47(1-3):199-204.

4. Lempert KD, Kopp JB. Renal Failure Patients in Disasters. Disaster Med Public Health Prep. 2019;13(4):782-90.

5. Kenney RJ. Emergency preparedness concepts for dialysis facilities: reawakened after Hurricane Katrina. Clinical journal of the American Society of Nephrology: CJASN. 2007;2(4):809-13.

6. Anderson AH, Cohen AJ, Kutner NG, Kopp JB, Kimmel PL, Muntner P. Missed dialysis sessions and hospitalization in hemodialysis patients after Hurricane Katrina. Kidney international. 2009;75(11):1202-8.

7. Howard D, Zhang R, Huang Y, Kutner N. Hospitalization rates among dialysis patients during Hurricane Katrina. Prehosp Disaster Med. 2012;27(4):325-9.

8. Lukowsky LR, Dobalian A, Goldfarb DS, Kalantar-Zadeh K, Der-Martirosian C. Access to Care for VA Dialysis Patients During Superstorm Sandy. Journal of primary care community health. 2019;10:2150132719863599. 
9. Santoro D, Benedetto F, Mondello P, Pipitò N, Barillà D, Spinelli F, et al. Vascular access for hemodialysis: current perspectives. Int J Nephrol Renovasc Dis. 2014;7:281-94.

10. Yan Y, Ye D, Yang L, Ye W, Zhan D, Zhang L, et al. A meta-analysis of the association between diabetic patients and AVF failure in dialysis. Ren Fail. 2018;40(1):379-83.

11. Suri RS, Larive B, Sherer S, Eggers P, Gassman J, James SH, et al. Risk of vascular access complications with frequent hemodialysis. Journal of the American Society of Nephrology: JASN. 2013;24(3):498-505.

12. Ellingson KD, Palekar RS, Lucero CA, Kurkjian KM, Chai SJ, Schlossberg DS, et al. Vascular access hemorrhages contribute to deaths among hemodialysis patients. Kidney international. 2012;82(6):686-92.

13. Astor BC, Eustace JA, Powe NR, Klag MJ, Fink NE, Coresh J. Type of vascular access and survival among incident hemodialysis patients: the Choices for Healthy Outcomes in Caring for ESRD (CHOICE) Study. J Am Soc Nephrol. 2005;16(5):1449-55.

14. Eslami MH, Zhu CK, Rybin D, Doros G, Siracuse JJ, Farber A. Simple predictive model of early failure among patients undergoing first-time arteriovenous fistula creation. Ann Vasc Surg. 2016;35:46-52.

15. Lopez-Cardalda G, Lugo-Alvarez M, Mendez-Santacruz S, Ortiz-Rivera E, Bezares E. Learnings of the Complete Power Grid Destruction in Puerto Rico by Hurricane Maria2018. 1-6 p.

16. FEMA. 2017 Hurricane Season FEMA After-Action Report. Washington, DC; 2018 July 12, 2018.

17. Rodríguez-Díaz CE. Maria in Puerto Rico: Natural Disaster in a Colonial Archipelago. Am J Public Health. 2018;108(1):30-2.

18. Alcorn T. Puerto Rico's health system after Hurricane Maria. The Lancet. 2017;390(10103):e24.

19. Kuss O, editor How to use SAS for logistic regression with correlated data. Proceedings of the 27th annual SAS users group international conference; 2002.

20. Lalonde TL, Nguyen AQ, Yin J, Irimata K, Wilson JR. Modeling correlated binary outcomes with timedependent covariates. Journal of Data Science. 2013;11(4).

21. Norris K, Harford R, Flaque J, Rodriguez Y, Harford M. SUN-192 MISSED, HEMODIALYSIS TREATMENTS AND MORTALITY IN PUERTO RICO BEFORE AND AFTER THE. 2017 HURRICANES: A MEDIUM DIALYSIS ORGANIZATION EXPERIENCE. Kidney International Reports. 2020;5(3):279-S80.

22. Lin C-j, Pierce LC, Roblin PM, Arquilla B. Impact of hurricane sandy on hospital emergency and dialysis services: a retrospective survey. Prehospital Disaster Med. 2014;29(04):374-9.

23. Martín Y, Cutter S, Li Z, Emrich C, Mitchell J. Using geotagged tweets to track population movements to and from Puerto Rico after Hurricane Maria. Population and Environment. 2020.

24. Tracking People on Dialysis

Hick J. Evacuating, Treating. and Tracking People on Dialysis: Lessons Learned from the 2017 Hurricane Season. The Exchange [Internet]. 2018 2/9/2018; 1(6):[12 - 4 pp.]. Available from: https://asprtracie.s3.amazonaws.com/documents/aspr-tracie-the-exchange-issue-6.pdf. 
25. Saran R, Robinson B, Abbott KC, Agodoa LY, Albertus P, Ayanian J, et al. US renal data system 2016 annual data report: epidemiology of kidney disease in the United States. American journal of kidney diseases. 2017;69(3):A7-8.

\section{Figures}

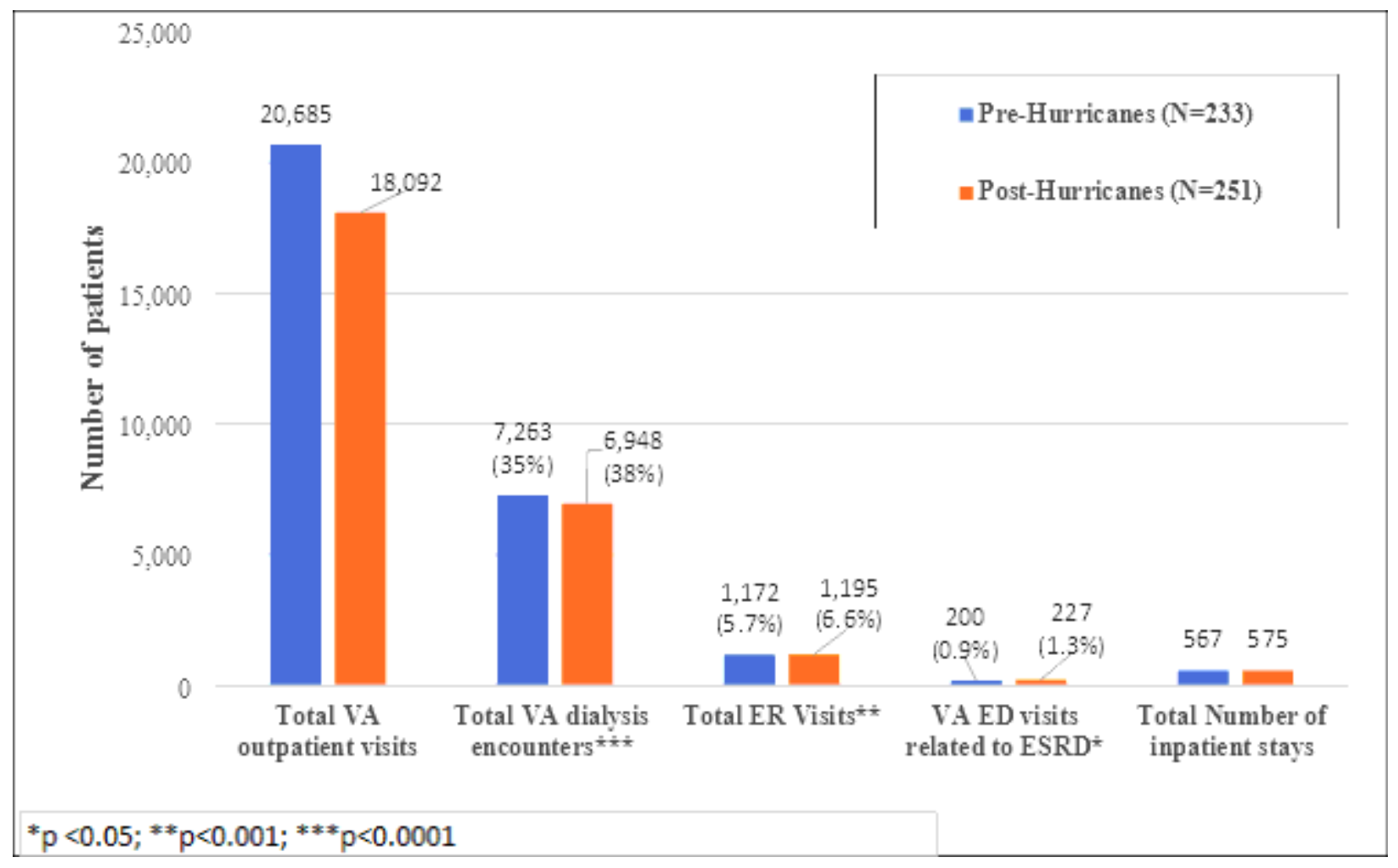

\section{Figure 1}

The number and percent of encounters for VA ESRD patients at SJVAMC, pre/post Hurricanes Irma and Maria 